Open Access

\title{
Impact of teacher-student writing conferences on frequency and accuracy of using cohesive devices in EFL students' writing
}

Abdullah Rajab Alfalagg (1)

Correspondence: binhweid83@ gmail.com

TESOL \& Applied Linguistics, Hadhramout University, College of Arts, Mukalla, Yemen

\begin{abstract}
While the bulk of feedback studies have focused on written corrective feedback, oral feedback in teacher-student writing conferences in EFL context has been underexplored. This article investigated teacher oral feedback based on the tenets of sociocultural theory. It examined the impact of teacher-student writing conferences on students' accuracy and frequency of cohesive devices employment. The study followed a quasi-experimental design with a pre-test, intervention and post-test. Data were collected from an intensive writing course for intermediate students at the college level. Based on guided-free writing prompts, the students had to write argumentative paragraphs of about 150-180 words followed by individual conference sessions to offer them oral feedback. The findings showed that oral feedback in writing conferences statistically impacted the students' writing performance with huge effect size (Cohen's $d=2.19$ ). Moreover, the results demonstrated empirical evidence that writing conferences positively impacted the students' frequency of employing referential markers ( $\mathrm{t}$ value $=-3.011 ; p=0.006<$ 0.05 ) and conjunctions (t value $=-2.200 ; p=0.039<0.05$ ). Further, oral feedback statistically impacted the students' accuracy of utilizing referential markers ( $\mathrm{t}$ value $=$ $-6.874 ; p=0.000<0.05$ ) and conjunctions (t value $=-7.253 ; p=0.000<0.05$ ). Writing conferences provided mediated learning experience for the students. The oral feedback assisted the students to decrease the overuse of the first, second person pronouns and the definite article 'the' with generic meaning in their writing. Instead, they depended on noun phrases and the third person pronouns which contributed to the text overall cohesion by creating explicit chains of references to the antecedents within the textual environment. Also, oral feedback helped the students to use conjunctions appropriately and accurately, so their texts were written densely cohesive. Pedagogical implications were discussed at the end of the article.
\end{abstract}

Keywords: Teacher-student writing conferences, Oral feedback, Cohesion, Referential markers, Conjunctions, EFL students 


\section{Introduction}

Little attention has been paid to contextual and socio-cultural dimensions of teacher's feedback (Lee, 2014) where knowledge is structured socially through interaction (Hyland \& Hyland, 2006; Vygotsky, 1978). Feedback in the socio-cultural theory is necessarily dialogic in order to be catered to learners' potential developmental level (Aljaafreh \& Lantolf, 1994; Sheen \& Ellis, 2011). It should be conversational rather than written feedback which lacks social interaction. It features some essential characteristics: (a) it is conversational, (b) interactive in the sense that it engages students in the process of exploring their weaknesses; (c) it is graduated and contingent, i.e. withdrawn depending on students' autonomous functioning (Aljaafreh \& Lantolf, 1994). In other words, the tutor is involved in dynamic assessment of the learner's status of functioning until s/he is ready to assume full responsibility of self-correction.

Feedback research has "largely been non-contextual and non-social focused largely on texts and conducted in a linear model of teacher respond and student revise" (Goldstein, 2006, p. 158). Conventional written feedback is typical for teacher-dominated product oriented writing classes where teachers use error codes randomly and respond to errors in an unfocused manner (Lee, 2014). Therefore, students are disengaged in the process of written feedback. Such sort of written feedback has fallen short due to the lack of interaction between the teacher and students.

Notwithstanding the abundance of research studies on the impact of teachers' written feedback, its contribution to writing development is still unclear (Solloway, 2016) and teachers often have a sense that they are not making full use of its potential (Hyland, 2003; Hyland \& Hyland, 2006).

Teacher-student writing conference in the present study refers to an individual meeting between the teacher and a student in order to discuss a first draft and offer interactive oral feedback. The meeting is conducted in a thoughtful, pre-determined manner and in a furnished conference room in a face-to-face format. The teacher's main role is to ask the student guiding questions on his/her potential writing competence based on his/her cohesive errors to assist him/her explore them. After the conference, the student is required to revise his/her first draft and rewrite a second draft accordingly.

\section{Cohesion as a persisting challenge to L2 student-writers}

Proper employment of cohesive devices has consistently been reported to pose challenges for beginner and proficient L2 student-writers in both ESL and EFL contexts. L2 student-writers use cohesion differently than native speakers of English do, over-using, under-using, or misusing cohesive devices (Hinkel, 2001; Kwan \& Yunus, 2014; Reid, 1992). Arabic L1 learners of English encounter humongous challenges to employ conjunctions appropriately (Alfalagg, 2015; Darweesh \& Khadhim, 2016). They overuse coordinate additive conjunctions while writing (Alfalagg, 2015;Hinkel, 2001 ; Reid, 1992). Also, they overuse references while writing and they use them to refer to vague referents (Hinkel, 2001; Reid, 1992). Not only Arabic learners of English encounter difficulties using references consistently, but also EFL students in different contexts (Al-Jarf, 2001; Liu \& Braine, 2005; Ong, 2011; Yang \& Sun, 2012). In addition, studies consistently find that the use of the definite article 'the' poses enormous challenges to EFL student-writers in different settings (Alhaysony, 2012; Crompton, 2011; Ong (2011). Different cohesive devices require different skills to be mastered (Al-Jarf, 2001). 
Kwan and Yunus (2014) find that lexical cohesion errors pose the most challenges followed by references and conjunctions as the least challenging. However, Ong (2011) point out that references pose the most challenges followed by lexical cohesive errors and conjunctions come as the least challenges. This contradictory result might be attributed to the differences in participants' proficiency level, teaching methods and objectives of the two studies. Interestingly enough, cohesive errors are treatable and they diminish with learners' increasing level of proficiency (Kwan \& Yunus, 2014; Yang \& Sun, 2012).

\section{EFL studies on writing conferences}

Writing conferences have been used to assist ESL learner mostly and recently EFL learners to overcome different erroneous linguistic features. Experimental studies in EFL context have been scarce. The contribution of writing conferences to enhance EFL students' writing ability is inconclusive though their efficacy has been widely investigated and showed impressive results with ESL students (Aljaafreh \& Lantolf, 1994; Erlam, Ellis, \& Batstone, 2013; Nassaji \& Swain, 2000). Cepni (2016) replicated Erlam et al. (2013) study. Both studies aimed at comparing whether Graduated Feedback or Explicit Feedback was successful in enabling self-correction and uptake of teacher's interactions in writing conferences. The latter was conducted in ESL context while the former was conducted in EFL context. Fourteen Turkish university students in the Dept. of English participated in Cepni's (2016) study. Both studies corroborated that students in the Graduated Feedback Group were able to self-correct their errors more than students in the Explicit Feedback Group, but they may not internalize the feedback every time. Gonzalez, Da Vinci, Victoria, and Tamaulipas (2010) compared the impact of teacher-student writing conferences versus teacher written corrective feedback on text revision, types of revision made and contribution of feedback types to revision. Seven Mexican students in a private high school participated in the study. The findings of the study showed that teacher written corrective feedback yielded more revisions than writing conferences did. Both written feedback and teacher-student writing conferences rendered teacher-based correction rather than student-initiated correction. Also more corrections were surface modification than text-based changes ( $84 \%$ versus 16\%) respectively. Leung's (2008) study investigated whether oral feedback in teacherstudent conferences might influence students' content and grammatical accuracy more than written feedback. Thirty-four sixth-year high school in Hong Kong were randomly assigned to either an experimental group or control group, with the former received oral feedback in the format of conferencing and the latter received written corrective feedback. The findings revealed a statistically significant difference in favor of the experimental group with a large effect size for writing conferences impact. Leung's (2008) study and the study of Gonzalez et al. (2010) showed contrary results. This contradiction could perhaps be attributed to the number of writing tasks utilized to collect the data, duration of the two studies, and the method of oral feedback delivery in the conferences as well as the analysis of writing conferences in each study.

\section{Aims of the study}

It is hypothesized that teacher-student individual writing conferences would positively impact cohesion in EFL students' writing. Based on this main hypothesis, the study 
primarily investigated whether individual teacher-student writing conferences in EFL context had impact on the students' utilization of two cohesive devices. To investigate the impact of teacher-student writing conferences, the study addressed the following research questions:

1. How does teacher oral feedback in teacher-student writing conferences impact EFL students' overall writing performance?

2. How does teacher oral feedback in writing conferences impact the students' frequency of using the cohesive devices: (a) conjunctions and (b) referential markers?

3. Does teacher oral feedback in writing conferences have an impact on the accurate employment of (a) conjunctions and (b) referential markers?

\section{Participants of the study}

The sample of the study consisted of 23 adult students in EFL context. Their English language proficiency was intermediate and their ages ranged between 20 and 22 years. English language was introduced to them at the primary school when they were at about 13 years of age. They had 7 years of exposure to English as a school subject. They were selected based on their passing performance in an adopted writing proficiency test from Edwards (2008) for A2-B1 difficulty level according to Common European Framework of Reference (CEFR). They enrolled to take an introductory intensive writing course of $66 \mathrm{~h}$ in a private English language institute. The vast majority of the participants were second year pre-service student teachers pursuing their BA in English at College of Education, Hadhramout University. However, during the present study they did not go to the college due to the prevailing unstable political situation in Yemen in 2015.

Teacher-student writing conferences have never been used in the college to offer feedback on their writings. Teaching writing skill at colleges of education in Yemen is theoretical (Assaggaf, Stapa, \& Mustafa, 2012; Muthanna, 2016). Mostly no hands-on writing activities at the text level are assigned to the students to practice writing and no feedback is given. When some teachers assign writing activities, they hardly follow up the students to submit first drafts to receive feedback. Besides, although cohesion is introduced in the syllabus of academic writing, it is not clearly delineated or emphasized. At best, instructors make a rough mention of the definition without explicating to the students what the cohesive devices are. They do not demonstrate to them how to use the different cohesive devices appropriately in writing. Also, teaching writing skill is usually assigned to junior teaching faculty members who lack expertise and professional training in English language teaching. They are holders of Bachelor's degrees from the same college or might have Master's degrees in linguistics or literature.

\section{Methodology design and data collection}

The current study followed a quasi-experimental design with a pre-test, intervention, and a post-test. The data were triangulated at the phase of collection, analysis, and interpretation to draw a full picture of the impact of the writing conferences. The study utilized a parallel version structure pre-test and post-test to collect the data. The preand post-test each consisted of a guided free writing prompt at the paragraph level and 
cloze-tests including the different subcategories of referential markers and conjunctions based on Halliday and Hasan's (1976) cohesion taxonomy. The collected data was comprised of 46 scripts of the pre-test and post-test.

\section{Data collection and treatment}

The intervention involved input sessions of explicit instruction and hands-on classroom writing activities. The former was based on pedagogical materials comprising of basic paragraph organization, pre-writing strategies, referential markers, and conjunctions. The latter involved guided-free writing prompts followed by one-to-one writing conferences. After the input sessions were completed, the participants were engaged in writing instructions of integrated reading and writing and hands-on writing activities. Based on guided-free writing prompts, they had to write paragraphs of about 150-180 words inside the classroom. After finishing the first drafts, each participant was scheduled for a writing conference with the teacher-researcher. He read, appraised and annotated the students' text before the conference sessions. It is note-worthy that the teacher-researcher, who offered the writing conferences, had been professionally trained at Murray State University (MSU), KY, U.S.A. He worked for one academic year as a part-time tutor in the university writing center.

\section{Procedures to offer oral feedback in the writing conferences}

The main function of the oral feedback was to draw the students' attention to their errors implicitly. Therefore, the feedback was ordered sequentially following strategies graded from self-regulation, very implicit and moved gradually to other regulation, explicit feedback strategies. It engaged the students in discussions, creating an environment of social interaction and negotiation of meaning. On this basis, the feedback was collaborative, dialogic, contingent, and graduated. The researcher provided the correction only as the last resort when the students could not correct their errors. A regulatory scale was devised to tailor the feedback to the students' needs based on previous studies and recommendations in the literature (Aljaafreh \& Lantolf, 1994; Ferris \& Hedgcock, 2005; Hyland \& Hyland, 2006). The following steps illustrate the basic procedures followed to offer the feedback in the writing conferences in the current study.

0 . The researcher hints to the learner to self-correct annotated errors before they come for the conference, after he had read, appraised, and annotated the texts.

1. During the conferences after brief welcoming remarks, the researcher asks the student to read his paragraph aloud and try to self-correct any error focusing on using conjunctions and/or referential markers.

2. The researcher prompts the student to read the sentence that contains the errors (conjunction/reference).

3. When there is an error in a conjunction/referential marker, and the student does not stop to self-correct it, the researcher indicates that something maybe wrong in the segment (intra sentential or inter sentential) - "Is there anything wrong in the sentence/ between the sentences?" [He points to the sentence/sentences/clause/line]. 4. If the student cannot self-correct the error, the researcher politely rejects the student's unsuccessful attempts at recognizing the error. 
5. Now, the researcher goes a step further to provide a more explicit feedback. He narrows down the location of error -"Is the error intra sentential or inter sentential?" [He taps on the table/ reads/ point to the part/phrase/clause that contains the error.] 6. The researcher indicates the nature of error to elicit correction. He does not identify the exact error in this step. He asks guiding questions like: "Is the reference correct?/There is something wrong here with the referential marker. Have you considered plural-number-position-possession? What is the link between ideas? Is the relation between the ideas additive/ contrastive/ sequence/ causal? Is the link captured using the most appropriate conjunction? There is something wrong here with your use of conjunction. /You need a better conjunction here to connect ideas."

7. The researcher now identifies the error to elicit correction by asking direct questions about the error. For example: "You can't use this conjunction here! Where is the conjunction to express addition? You have not used it! What does this pronoun refer back to? The agreement of number/location is not correct in this pronoun. You have missed the referential marker for the subject/object".

8. In case of unsuccessful attempts, the researcher rejects the student's unsuccessful attempts politely when the cue questions have failed to identify the error.

9. The researcher provides the correct form as the last resort without any explanations.

10. In addition to the correct form, the researcher provides example and metalinguistic explanation in case the same type of error is repeated. For example: "Last night I went to bed late AND I woke up early this morning?" (incorrect). "Last night I went to bed late BUT I woke up early this morning?" (correct as it marks a contrastive relation and not an additive relation). "As Yemen is an unstable state, it is difficult for common people to live peacefully. We are using 'as' to indicate a cause why people in Yemen cannot live peacefully these days. So this is a CAUSAL relation that we capture by using a marker 'AS'.

\section{Administering the writing conferences}

Each writing conference lasted approximately 15 to $30 \mathrm{~min}$. Arabic language was used mostly as the medium to offer feedback due to the students' limited spoken proficiency in English and importantly to serve the purpose of conferencing i.e. to scaffold students' self-correction. The conferences were held individually, face-to-face in a well-equipped conference room; different room from the regular classroom. The researcher and the student sat around a circle-shaped table at culturally appropriate proximity to discuss the student's first drafts. Being in an Islamic culturally dominated society, the female participants' were given the option to sit for the writing conferences individually or in pairs. They opted for individual conferences due to the privacy and anxiety free setting.

The researcher and the students handled several roles throughout the writing conferences. The researcher's main role was scaffolding the students' self-correction following the regulatory scale. He directed them to self-correct their texts with the minimum assistance sought in subsequent writing. Also, he welcomed the students cordially at the beginning of the writing conferences and he drew their attention to the main goal of the conference, i.e. focusing on the cohesive errors. The students' roles included reading their texts aloud, asking questions, attempting self-correction and taking notes on 
their drafts. At the end of the conferences, they recapitulated the errors discussed and how they should be corrected in the second draft. After the conference, the students revised their first drafts according to the received feedback, rewrote second drafts and they submitted them.

\section{Framework of data analysis}

The analyses relied on error analysis of the referential markers and conjunctions. The quantitative analysis was conducted in two different ways; grading the students' texts and error analysis. First, three raters, including the researcher, assessed and awarded scores to pre-test and post-test scripts based on an answer key, a grading rubric and a model answer. They were doctoral researchers and they were trained by the researcher on using the rubric and on error analysis. Inter-rater reliability was calculated using Cohen's kappa ( $\kappa$ ) through SPSS and outstanding agreement was observed.

Next, the cohesive devices were analyzed based on error analysis (Brown, 2007; Ellis, 2008; Ellis \& Barkhuizen, 2005; Johansson, 1973). Accordingly, erroneous employment of referential markers was classified into:

1. Inconsistency: It refers to the inconsistent use of references inter or intrasententially.

2. Addition: It occurs when a particular cohesive device is unnecessarily used.

3. Substitution: It occurs when a particular cohesive device is used wrongly in substitution of another correct one.

4. Omission: It occurs when a particular cohesive device is expected in the text but it is missing.

Error analysis was carried out systematically through the following measures. First, the scripts were adjusted to 160 words long as the maximum word limit for error analysis in order to avoid any bias for higher frequency of the cohesive devices in long texts. Second, the raters first read the scripts and painstakingly identified and tagged all the tokens of referential markers and conjunctions in the texts. After that, the raters read the same script again and reconstructed the identified erroneous use of the cohesive devices on the students' scripts. The different tokens of the cohesive devices were marked using different colors based on their subcategories. The incorrect uses of the cohesive devices were colored and marked with a circle. The differently colored tokens and the erroneous circled cohesive devices differentiated the correct and incorrect devices. These coding procedures yielded the row numerical data of frequency and accuracy. Third, the identified and coded row frequency of the cohesive devices were counted, tabulated and classified into their subcategories according to Halliday and Hasan's (1976) cohesion taxonomy. Incorrect tokens of cohesive devices were identified with an asterisk $\left({ }^{*}\right)$ on the table and missing cohesive devices were marked with the symbol $(\wedge)$. The students' grammatically violated rules were described in relation to adult-like target grammar and then reconstructed. The main criteria to judge a structure as incorrect was conformity to formal written grammar rules of English, message intelligibility and acceptability as a secondary measure (Ellis, 2008; Johansson, 1973). Although it was not possible to arrive at a single authoritative reconstruction for the 
students' incorrect use of the cohesive devices, the raters agreed about most of the erroneous structures.

Halliday and Hasan's (1976) cohesion taxonomy was adopted as a model for the analysis of the cohesive devices. Meanwhile, some modifications enlightened by Carrell (1982, 1984) were made for theoretical and practical considerations. Every single reference was tallied while coding the referential markers. Accordingly, the first and second personal pronouns were considered for coding because they are typical feature in EFL learners' interlanguage development (Hinkel, 2004). Also, every occurrence of the definite article 'the' was coded without making a distinction between cataphoric and anaphoric definite article. The definite article 'the' rarely occurs in a purely anaphoric condition (Halliday \& Hasan, 1976).

In addition, the occurrences of the zero-article noun phrases were considered for analysis for the following reasons. Zero-article noun phrases were coded in order to control errors of the definite article 'the'. In the participants' mother tongue, the definite article (the-ال التعريف) is used to express generic meaning identical to the function of zero article in English. Also, employment of the zero article noun phrases was considered for analysis to guard against the students 'avoidance strategy'. The interface between the accurate use of the definite article and the zero article may overshadow the impact of the treatment if zero-article noun phrases were not considered for analysis. For example, the students may erroneously overuse the definite article in the pre-test based on their L1. When their erroneous employment of the definite article disappears in the posttest, using zero-article for generic reference, this treatment impact would not be clear without considering zero-article noun phrases for analysis. Further, the argumentative nature of the writing tasks entails occurrences of the zero-article generic noun phrases. Therefore, they were included in the analysis in order to unequivocally and fairly probe the impact of oral feedback on the use of the definite article 'the'.

\section{Results and discussion}

\section{Impact of writing conferences on students' writing scores}

The findings of the study revealed that the intervention and the teacher-student individual writing conferences positively impacted the students' employment of conjunctions and referential markers and they enhanced their overall writing performance.

Table 1. displays participants' overall mean scores in the pre- and post-test and the results of the paired sample t-test. The mean score in the post-test was higher than it was in the pre-test. The t-test results showed that subjects' difference in performance was statistically significant. Calculating the effect size, huge magnitude of difference was observed (Cohen's $d=2.19$ ).

In addition, the qualitative analysis demonstrated that the students' post-test scripts were written more cohesively and coherently in terms of content elaboration,

Table 1 Mean Score, Standard Deviation, and Paired Sample t-test Results of the Pre- \& Post-test

\begin{tabular}{llllll}
\hline Test & $\boldsymbol{M}$ & $\boldsymbol{S D}$ & $\boldsymbol{T}$ & $\boldsymbol{d f}$ & $\boldsymbol{P}$ \\
\hline Pre-test & 22.87 & 5.53 & 10.86 & 22 & .000 \\
Post-test & 32.96 & 3.74 & 9 & & \\
\hline P< & & & & \\
\hline
\end{tabular}

$P<.05$, two-tailed 
organization, appropriate use of referential markers and conjunctions. The remarkable improvement in the students' post-test performance can be interpreted as the effect of the writing conferences. The individualized feedback during conferences positively impacted the students' overall writing performance. This finding corroborates Leung' (2008) finding that Writing Conference Group exhibit significant difference in their performance with large effect size.

\section{Impact of writing conferences on frequency of cohesive devices}

Table 2 displays the mean frequency and the paired-sample t-test results of the conjunctions and referential markers used by the students in the guided-free writing tasks in the pre- and post-tests. As shown in the Table, the mean illustrated that there was an increase in the frequency occurrence of conjunctions in the post-test scripts. There was, however, a decrease in the frequency employment of the referential markers in the same test. The $p$-values of both conjunctions and referential markers indicated that difference was statistically significant. The $p$-values illustrate that the majority of the subjects increased their use of conjunctions and decreased their dependence on references in the post-test scripts. These findings indicated that the subjects' post-test scripts were more densely cohesive in terms of connectedness using conjunctions than their pre-test scripts. In terms of referential markers employment, the results indicated that the subjects depended heavily on referential markers to achieve cohesion in the pre-test, whereas their dependence on referential markers diminished in the post-test.

Tables 3 and 4 further explained the contrary results, i.e. the rise in use of conjunctions and the fall in the use of referential markers.

As demonstrated in Table 3, the increase in the use of causal conjunctions in the post-test was the most noticeable. Their frequency increased more than two times in the post-test scripts than they were in the pre-test scripts. This result indicated that the participants employed more causal conjunctions after the intervention. In the pre-test scripts, causal conjunctions ranked the third after additive and temporal respectively, whereas in the post-test scripts causal conjunctions ranked the second most commonly employed conjunction subcategory after additive conjunctions with a significant rise. The guided writing prompts in both the pre- and post-test were argumentative in nature and the subjects were required to take a position regarding the topic and to explain the reasons. The qualitative analysis showed that most of the subjects failed to explain the reasons in the pre-test scripts and their writings were obscure. Their texts lacked details and tended to be informal narrative.

Table 2 Mean frequency, standard deviation, and paired sample T-test results for conjunctions and references

\begin{tabular}{lllllll}
\hline Cohesive devices & Test & $\boldsymbol{M}$ & $\boldsymbol{S D}$ & $\boldsymbol{t}$ & $\boldsymbol{d f}$ & $\boldsymbol{P}$ \\
\hline Conjunctions & Pre-test & 13.65 & 5.79 & -2.200 & 22 & .039 \\
& Post-test & 15.91 & 4.33 & & & \\
References & Pre-test & 29.91 & 11.01 & -3.011 & 22 & .006 \\
& Post-test & 23.26 & 7.11 & & & \\
\hline
\end{tabular}

$P<.05$, two-tailed 
Table 3 Mean frequency, standard deviation and percent of the subcategories of conjunctions

\begin{tabular}{lllll}
\hline Conjunctions & Test & $\boldsymbol{M}$ & $\boldsymbol{S D}$ & Percent \\
\hline Overall conjunctions & Pre-test & 13.65 & 5.78 & $8.29 \%$ \\
& Post-test & 15.91 & 4.32 & $9.93 \%$ \\
Additive & Pre-test & 7.30 & 3.38 & $4.43 \%$ \\
& Post-test & 7.35 & 2.92 & $4.58 \%$ \\
Adversative & Pre-test & 1.59 & 1.59 & $0.92 \%$ \\
& Post-test & 1.26 & 1.39 & $0.79 \%$ \\
Causal & Pre-test & 2.41 & 1.89 & $1.40 \%$ \\
& Post-test & 4.57 & 2.25 & $2.85 \%$ \\
Temporal & Pre-test & 2.64 & 2.17 & $1.53 \%$ \\
& Post-test & 2.74 & 1.45 & $1.71 \%$ \\
\hline
\end{tabular}

Table 4 shows that the first and second personal pronouns ranked the first most commonly employed subcategory amongst the referential markers in the pre-test scripts. It is apparent that they outnumbered the third personal pronouns in the pre-test scripts. Surprisingly, the first and second personal pronouns were even utilized at a higher frequency rate than the zero article noun phrases, which should have constituted a substantial portion of lexical cohesion in the texts. This finding revealed that the subjects depended heavily on the first and second personal pronouns than any other cohesive device rendering their pre-test scripts as vague narrative. First and second personal pronouns did not refer explicitly to a certain antecedent in the textual environment of the paragraphs. They did not contribute to the cohesion of the text according to the Halliday and Hasan's (1976) cohesion taxonomy. Also, the abundant employment of first and second person pronouns in the pre-test scripts illustrated that the texts were informal and tended to be narrative and more of spoken discourse (Hinkel, 2004).

However, in the post-test scripts, the frequency of the first and second person pronouns, on the one hand, and the third person pronouns on the other hand were

Table 4 Mean frequency, standard deviation, and proportion of referential markers subcategory

\begin{tabular}{lllll}
\hline Referential Markers & Test & $\boldsymbol{M}$ & SD & Percentage \\
\hline Overall References & Pre-test & 29.91 & 11.01 & $18.16 \%$ \\
& Post-test & 23.26 & 7.11 & $14.51 \%$ \\
1st \&2nd Personal Pronouns & Pre-test & 11.91 & 6.11 & $7.23 \%$ \\
& Post-test & 7.00 & 4.81 & $4.37 \%$ \\
3rd Personal Pronouns & Pre-test & 9.52 & 5.17 & $6.03 \%$ \\
\multirow{3}{*}{ Demonstrative Pronouns } & Post-test & 11.57 & 4.97 & $7.22 \%$ \\
\multirow{3}{*}{ Comparative Pronouns } & Pre-test & 2.39 & 1.85 & $1.52 \%$ \\
\multirow{3}{*}{ The definite article 'the' } & Post-test & 1.52 & 1.34 & $0.95 \%$ \\
& Pre-test & 1.22 & 1.48 & $0.77 \%$ \\
The zero article & Post-test & 0.43 & 0.66 & $0.27 \%$ \\
& Pre-test & 5.09 & 3.04 & $3.09 \%$ \\
\hline
\end{tabular}


reversed. The frequency of the third person pronouns outnumbered the frequency of the first and second person pronouns. The third person pronouns ranked the first amongst the referential markers subcategory in the post-test scripts. The first and second person pronouns frequency decreased substantially close to half. At the same time, the decrease in frequency of the first and second person pronouns was associated with a substantial increase in the frequency employment of lexical cohesive devices manifested by the rise in the frequency uses of the zero-article noun phrases in the post-test scripts. They ranked as the first cohesive device followed by the third person pronouns. Further, the frequency uses of the definite article 'the' in the post-test scripts decreased about two times than they were in the pre-test scripts. The uses of the definite article in the pre-test scripts were most often incorrect over-use. In addition, the demonstrative pronouns frequency uses in the post-test scripts decreased to about half in the pretest scripts. They were employed vaguely and inconsistently, but these errors diminished in the post-test scripts. These findings can be interpreted in relation to the effect of the independent variable of the study. These results demonstrated that the writing conferences positively impacted the subjects' frequency of employing conjunctions and referential markers. They assisted the students to respond to the writing prompt properly by employing causal conjunctions to explain their position about the topic in their post-test scripts according to the nature of the writing prompt.

The decrease in mean frequency employments of the first and second person pronouns and increase in the frequency of the third person pronouns in the post-test scripts were in favor of the subjects' performance. They depended on the third person pronouns and lexical cohesion to maintain cohesion in the post-test scripts. The use of the third person pronouns contributed to the cohesiveness of the texts by creating explicit chains of references to the antecedents within the textual environment (Hinkel, 2004). Hence, the students' post-test scripts were more cohesive in terms of lexical repetition and clear chains of anaphoric references. This finding is congruent with Shaw and Liu (1998) who found that students' texts become less like speech and more like conventional academic written English over a three-month course, though they did not use writing conferences in their study.

\section{Impact of writing conferences on accuracy of cohesive devices}

In Table 5., the mean errors demonstrated that there was a substantial fall in the erroneous conjunctions and referential markers in the subjects' post-test scripts. Table 6 presents the frequency, the accuracy percentage and proportion of the employment of conjunctions and referential markers. Table 7 shows the mean errors and the paired

Table 5 Mean errors, standard deviations, and paired-sample T-test results of conjunctions and references

\begin{tabular}{lllllll}
\hline Cohesive Devices & Test & $\boldsymbol{M}$ & $\boldsymbol{S D}$ & $\boldsymbol{t}$ & $\boldsymbol{d f}$ & $\boldsymbol{P}$ \\
\hline Conjunctions & Pre-test & 5.30 & 2.89 & -7.253 & 22 & .000 \\
& Post-test & 0.91 & 0.90 & & & \\
References & Pre-test & 12.82 & 6.19 & -6.874 & 22 & .000 \\
& Post-test & 2.70 & 1.63 & & & \\
\hline
\end{tabular}

$P<.05$, two-tailed 
Table 6 Frequency, proportion, and ratio of correct/incorrect employment of conjunctions and references

\begin{tabular}{lllllll}
\hline Cohesive devices & Test & $\boldsymbol{M}$ & SD & Percent & Ratio of correct & Ratio of incorrect \\
\hline Conjunctions & Pre-test & 13.65 & 5.78 & $8.29 \%$ & 61.15 & 38.85 \\
& Post-test & 15.91 & 4.32 & $9.93 \%$ & 94.26 & 5.74 \\
References & Pre-test & 29.91 & 11.01 & $18.16 \%$ & 57.12 & 42.88 \\
& Post-test & 23.26 & 7.11 & $14.51 \%$ & 88.41 & 11.59 \\
\hline
\end{tabular}

sample t-test results of the subjects' performance in the cloze-tests in the pre- and post-test. The $p$-values in both Tables 6 and 7 illustrated that the difference in mean errors between the pre-test and post-test was statistically significant. These findings can be interpreted in relation to the effect of the individualized oral feedback. The writing conferences impacted the students' accuracy employment of the conjunctions and referential markers manifested by the decrease in the subjects' erroneous uses in posttest in both the cloze-test as well as the guided free writing tasks. This finding concurs with Aljaafreh and Lantolf (1994) who find that parrticipants appropriated the feedback and demonstrated greater responsibility over the production of the targeted structures in later sessions.

Error analysis revealed that the errors in the use of referential markers abounded excessively in the subjects' pre-test scripts, so they hindered message intelligibility and rendered their scripts vague. The referential errors were classified into five types illustrated by the sample excerpts from the students' scripts.

\section{Errors in the employment of pronouns Inconsistent use of pronouns}

In the pre-test scripts, many students were unable to use pronouns consistently within and between sentences. The inconsistency occurred in three cases. The students shifted from the first person pronouns to the second person pronouns or vice versa. Second, they used pronouns inconsistently in terms of number. They shifted using a singular pronoun to refer back to a plural noun phrase or they used a plural pronoun to refer back to a singular noun phrase. As a result, antecedents of these inconsistent references were unrecoverable from the context or yielded odd ideas. Third, the students shifted from using a base form of comparison in one clause to a comparative form in the second clause within or between sentences.

Table 7 Mean errors, standard deviation and paired sample t-test results of conjunctions and references in cloze-tests

\begin{tabular}{lllllll}
\hline Cohesive Devices & Test & $\boldsymbol{M}$ & $\boldsymbol{S D}$ & $\boldsymbol{t}$ & $\boldsymbol{d f}$ & $\boldsymbol{P}$ \\
\hline Conjunctions & Pre-test & 6.82 & 1.99 & -8.694 & 22 & .000 \\
& Post-test & 2.73 & 1.91 & & & \\
References & Pre-test & 2.56 & 1.32 & -3.016 & 22 & .006 \\
& Post-test & 1.30 & 1.99 & & & \\
\hline
\end{tabular}


1. For me, I think it is very nice for me to give gifts to others because that really values your feelings towards them and sometimes they will try to give you something back as a gift.

2. when $\boldsymbol{y} \boldsymbol{o u}$ are engaged $\boldsymbol{m} \boldsymbol{y}$ best friend give $\boldsymbol{m} \boldsymbol{e}$ promes the dinner and lunch on him, but I didn't forget his promes.

3. Sometime $\boldsymbol{w e}$ feel happy, but sometime [^ ${ }^{\wedge}$ we] feel angry. If the gift is refer to something good for $\boldsymbol{y o u}$ and the gift itself said thank for $\boldsymbol{y o u}$. In this case we will feel happiness.

\section{Addition of the definite article 'the' with generic nouns}

The most frequently misused cohesive device in the students' pre-test scripts was the definite article 'the'. The students overused the definite article 'the' with generic plural countable nouns, generic non-countable nouns, and generic singular countable nouns, while they were supposed to use zero-article noun phrases. Careful inspection of the students' previous scripts before the occurrences of the definite article revealed that their uses of the definite article did not refer back to a specific antecedent within their texts. Rather, it referred to generic uses of the nouns. It seems that the students translated ideas literally from Arabic into English and unconsciously they applied the rules of generic nouns in Arabic while writing in English. This finding is congruent with Crompton (2011). Generic meaning in Arabic is expressed with generic nouns attached to the definite article 'the- ال'.

1. there are a lot of things that you can do it in your society to cement the relationship with all the people ...

2. Some people use the gift to kill the police, as they do with some police men, somebody use the gift to joke with his friend,

3. For example, the parents gave their children the gifts when they got a high level on the school. Also, the mother didn't forget their birthdays and she appeared in the party ...

\section{Addition of pronouns}

The students unnecessarily used pronouns. They, therefore, had double subjects or objects within one clause causing syntactic errors. Also, they redundantly used pronouns which were either not recoverable because they did not refer back to a specific antecedent in the previous clause or they were merely repetition.

1. It's good to give someone a gift which he like and love $i t$.

2. The presents $i t$ doesn't matter how much money [^they] take ...

3. finally I think the givts [gifts] aren't something that you receive $\boldsymbol{i t}$...

\section{Substitution of pronouns}

The students used personal pronouns to refer to too remote antecedent noun phrases instead of noun phrases. They used demonstrative pronouns to refer to a vague idea in the preceding sentences. The antecedent could be an embedded idea in the previous sentences, an antecedent noun phrase in the previous sentence or an antecedent noun 
phrase in the same sentence with several noun phrases in between. In addition, the students substituted vague pronouns while they could have used other obvious pronouns to convey their message effectively.

1. There are so many occasions to give or receive gifts for example birthdays, widdings, turning back from traveling, and the list is endless. In addition to that sometimes we give or receive them for no any occasion.

2. Some people use the gift to kill the police, as they do with some police men, somebody use the gift to joke with his friend, but sometime the joke changes to big problem. Everyone as these people must not do as this. They must use it in good ways

3. I think that gift giving is something that is important in our life since $\boldsymbol{i t}$ gives $\boldsymbol{i} \boldsymbol{t}$ a nice test (طعم). So, it is like adding salt into the food to make it delicious.

\section{Omission of pronouns}

The students omitted necessary pronouns at clause level and sentential level such as subject or object pronouns. Missing pronouns rendered their texts incorrect syntactically. The missing pronouns were written in square parentheses and marked with $[\wedge]$ :

1. for example when they put a bad thing in a box in ceremony and give [^it] to their friend, and laughing at him.

2. When you give a gift to your grandmother, grandfather, father, mother or anyone

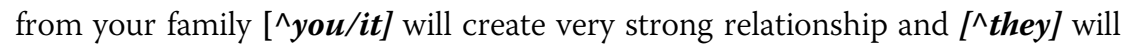
love you more.

3. The presents it doesn't matter how much money [^they] take but [^they] give a good reading from others.

\section{Errors in the employment of conjunctions} Addition of conjunctions

The most frequently added conjunctions in the pre-test scripts were the additive conjunctions, especially 'and' and 'also'. The students depended heavily on coordinate conjunctions to connect sentences. They were unable to separate main ideas from supporting ideas using proper punctuation marks; so their texts replete with run-on sentences. For instance, they unnecessarily used 'and' in intra-sentential position at phrase level to coordinate redundant nouns or verbs. They used 'and' and 'also' in inter-sentential position at clause level to coordinate too many ideas without using a full stop (.).

1. I feel very happy when someone gives me a gift and I really appreciate it so much regardless what kind of a gift it is and feel that I should give something in return to make him feel happy like what he did with me.

2. I think the givts [gifts] aren't something that you receive it no it is also some thing that you feel and a litter between your hurt [heart] you must read it correctly.

3. Usually people give gifts and presents in wedding, parties, and birthdays. 


\section{Omission of conjunctions}

The students were unable to use conjunctions when it was reasonable to use them in their pre-test scripts. For instance, they missed the coordinate additive conjunction 'and' while they were supposed to use it before the last item in a list. Also, they introduced examples to elaborate a main idea without using an exemplification transition. Similarly, when they explained cause/effect meaning relations, they did not use conjunctions to illustrate the causal meaning relations clearly. When they explained an opposite viewpoint, they did not use adversative conjunctions.

1. There are many occasions for giving gifts [^ ${ }^{\wedge}$ such as] birthdays, weddings, $\left[{ }^{\wedge}\right.$ and $]$ ceremonies.

2. [^When] You give a gift to your brother or your little sister on their birthday, maybe they will crying because they couldn't control their emotion.

3. You make all your gifts are positive. [^ For example,] I had [a story about] a negative aspect of gift giving ... .

\section{Substitution of conjunctions}

The students substituted erroneous conjunctions instead of appropriate conjunctions in their pre-test scripts. The substituted conjunctions were either within the same conjunction subcategory or from a different conjunction subcategory. Employing intrasubcategory substitution, the students used two conjunctions under the same subcategory interchangeably irrespective of their semantic function. For instance, within the additive subcategory they substituted 'and' and 'also' interchangeably. Similarly, they substituted 'For example' instead of 'such as' at intra-sentential position in order to enumerate a list of items. Within the temporal subcategory of conjunctions, they substituted 'finally' as a concluding transition instead of 'In conclusion, or In brief to conclude their paragraphs. Within the adversative conjunctions subcategory, the students substituted 'By another hand' or 'in the other side' instead of a normal adversative conjunction 'However'. Further, while some transitions are fixed formulaic expressions, such as 'on the one hand, on the contrary, therefore' the students unwittingly created their own transition signals such as in the other side/ by another hand/, for this/ for that'. With regard to inter-subcategory substitution of conjunctions, the students overused additive coordinate conjunction 'and' at the expense of the other subcategories. For example, while the text explained cause/effect meaning relations, the students used additive conjunctions instead.

1. As it known gifts make the relationships between people stronger also people got love each other more.

2. It's good to give someone a gift which he like and love it. In the other side, somebody change the gift affect from good to bad and [^he] make a bad picture for the gift

3. I think that some gifts are positive like, when you are engaged my best friend give me promes the dinner and lunch on him, but I didn't forget his promes so for this is the most expensive gift. By another hand there are some negative gift like ... 


\section{Conclusion and pedagogical implications}

The findings have provided compelling evidence confirming the positive impact of writing conferences on EFL students' employment of cohesive devices. Writing conferences transformed the students' overall writing performance as their texts were written cohesively, their ideas were elaborated and organized appropriately. The results demonstrated that oral feedback in writing conferences significantly impacted the students' accuracy and frequency of using conjunctions and referential markers. The students decreased the over dependence on the use of the first person pronouns, the second person pronouns and the definite article 'the' with generic noun phrases. Instead, they increased the use of the third person pronouns and zero noun phrases. In other words, they reduced the employment of the informal linguistic features and increased the employment of formal linguistic features similar to adult-like academic writing. Also, writing conferences assisted the students to use conjunctions appropriately and accurately, particularly causal conjunctions subcategory; so their texts were written densely cohesive.

The findings of the study demonstrated how writing conferences provided mediated learning experience for the students. The analysis of the pre-test scripts showed the students' poor employment of the cohesive devices before they were engaged in writing conferences. The growth exhibited in the analysis of the post-test scripts can be attributed to engaging the students in three rounds of writing conferences. Of paramount significance to the students' enhanced writing performance was their active interaction during these conferences. Based on the regulatory scale, graduated feedback was offered that ranged from very implicit to very explicit entailing self-corrections. Throughout three rounds of conferencing, the students' input, negotiations and quarries mediated their abilities to utilize the cohesive devices appropriately according to the writing prompts and accurately. The analysis of the post-test scripts exhibited the outcomes of the students' self-regulation culminating in their independent correction and accurate use of the cohesive devices. The results demonstrated that the students internalized the oral feedback largely and they gained a relative control over the employment of the cohesive devices almost as well as matured adult writers.

The impressive findings of the study have some significant pedagogical implications for EFL teachers, writing instructors, writing center tutors and policy makers of L2 writing in EFL context. Teachers in EFL context need to consider using teacher-student writing conferences to help students in expressing their ideas unequivocally. The present study has proved that individual teacher-student writing conference can be a viable option to offer students feedback on proper employment of cohesive devices. Previous studies have shown that cohesion is culturally determined (Mohamed-Sayidina, 2010; Weigle, 2002) and it is one of the most difficult aspects of language to teach to L2 students (Hinkel, 2002, 2004). To this end, oral feedback in writing conferences eased the complexity of using cohesive devices. During writing conferences, the students had the opportunity to ask about the cultural norms of employing cohesive devices and they were provided with individual and tailored feedback. The meaning negotiations between the researcher and the student explicate how referential markers might have been ambiguous in the students' texts. The students were provided with an expert advice to assist them in exploring their errors and fixing them. Active involvement of the students 
and meaning negotiations allowed the researcher to elucidate to the student how meaning relations in English language might be differently expressed than in the Arabic language and how different meaning relations are captured using the different conjunctions subcategories. For instance, while Anglo-American written discourse features subordination to exhibit sophisticated writing style (Hinkel, 2002; McNamara, Crossley, \& McCarthy, 2010), Arabic language prefers coordination and this style should be avoided while writing in English. Likewise, generic meaning in English is expressed using zero article generic plural countable nouns, generic noncountable nouns, and generic singular countable nouns phrases (Crompton, 2011). Generic meaning in Arabic language, however, is expressed by the definite article 'the' attached to the generic plural countable nouns and the definite article long with generic singular countable nouns. It is the interaction, meaning negotiations and students' invlovement during conferences that scaffold the students' development (Goldstein \& Conrad, 1990) to understand divergences between English and Arabic cohesive devices. Interaction and neogtiations acted as catalysts for making positive impacts on the students' writing performance. Meaning negotiation assisted the students of different proficiency levels to grow at their pace achieving their Zone of Proximal Development (Vygotsky, 1978) in terms of using the cohesive devices appropriately. Since no two students can perform identically, writing conferences provided exemplary method for individualized, and catered feedback.

The present study highly recommends establishing writing centers as a facility in universities to support the teaching of writing in EFL context. Writing centers would enable teachers to offer high quality conferencing. Writing conferening is worthy to be introduced to EFL context to support teaching writing bearing in mind the novelty of the writing conferencing method to provide students with feedback in Yemeni context. If $90 \%$ of educational institutions in the United States had introduced writing centers in the 1990s (Hobson, 2001) to support teaching writing to native speakers and ESL students, teaching writing in EFL context is in urgent need to establish writing centres. Teaching writing skill in EFL context is in need of introducing interactive, need-based, individually directed feedback strategies to help EFL students apply cohesive devices properly. Writing centers provide regular tutoring to students to assist them to become better writers, in addition to several other benefits they offer to both students and teachers. The phenomenal success of writing conferences in improving the students' cohesion indicates that regular conferencing in writing centers might help students overcome many other writing difficulties.

\section{Limitations of the study}

Some inevitable limitations should be taken into account while interpreting the findings of the study. First, explicit instruction of cohesion might had impact on the observed huge effect size of conferencing in the present study. It was unfeasible to separate the explicit instructional input sessions from the writing conferences. Therefore, the students had to take explicit instruction on cohesion before they write classroom assignments and afterwards they were offered interactive oral feedback on their cohesive device employment. Second, this study acknowledges the time consuming nature of writing conferences; so it recommends 
establishing writing centers as venues to offer conducive writing conferences. The study does not imply that writing conferences should be allocated a substantial amount of class time in an already prescribed curriculum. It simply attempts to draw the attention of instructors of writing and policy makers in higher education to the efficacy of individual oral feedback in the form of writing conferences in EFL context as a viable source for enhancing students writing ability.

\section{Acknowledgements}

This study was part of my doctoral research project and it was sponsored partially by a scholarship grant from Hadhramout University based on the order number (1/1/165) of the university rector. This study would not have been conducted without the smooth cooperation of the administration of Al-Tafawog English Language Institute for Vocational Training and Development, Tarim- Hadhramout. Thank you for welcoming me in your institute and offering the necessary logistic support. I am grateful to my PhD supervisor, Prof. Chanchala K Naik of the EFLU, for her insightful guidance and constant support. Special thanks go to the students who enrolled in the course Academic Writing I and the raters who spent their invaluable time scoring the pre and post-test and analyzing the students' errors.

\section{Author's contributions}

The present research article is part of my own doctoral research project. The author(s) read and approved the final manuscript.

\section{Author's information}

ABDULLAH RAJAB ALFALAGG works as an assistant professor of TESOL and Applied Linguistics at College of Arts, Hadhramout University, Yemen. He holds a doctorate degree in English Language Education from the English and Foreign Languages University, Hyderabad, India. He has obtained MA in TESOL from Murray State University, KY, U.S.A as a Fulbright scholar. He worked for 1 year as a part-time tutor at MSU Racer Writing Center during his MA study. Research interests: Developing EFL students' writing, reading and vocabulary, socio-cultural theory.

\section{Funding}

The present research article was self-funded. It was sponsored partially by a scholarship grant from Hadhramout University based on the order number (1/1/165) of the university rector. The author received monthly stipend from his university. The university has no any role in the design of the study, collection of data, analysis, interpretations of data and in writing the manuscript.

Availability of data and materials

Please contact author for data requests.

\section{Competing interests}

The author declares that he has no competing interests.

Received: 2 May 2020 Accepted: 11 November 2020

Published online: 17 November 2020

\section{References}

Alfalagg, A. (2015). ESL/EFL students' use of conjunctions to maintain cohesion in academic writing. Global English-Oriented Research Journal, 1(1), 29-42.

Alhaysony, M. (2012). An analysis of article errors among Saudi female EFL students: A case study. Asian Social Science, 8(12), 55-66. https://doi.org/10.5539/ass.v8n12p55.

Aljaafreh, A., \& Lantolf, J. (1994). Negative feedback as regulation and second language learning in the zone of proximal development. The Modern Language Journal, 78(4), 465-483.

Al-Jarf, R. (2001). Processing of cohesive ties by EFL Arab college students. Foreign Language Annals, 34, 141-151.

Assaggaf, H., Stapa, S., \& Mustafa, J. (2012). Investigating teaching and learning practices of second language ESP writing at tertiary level in Yemen. Arab World English Journal, 3(2), 48-75.

Brown, H. D. (2007). Principles of language learning and teaching. New Jersey: Pearson Education.

Carrell, P. (1982). Cohesion is not coherence. TESOL Quarterly, 16(4), 479-488.

Carrell, P. (1984). Comments on Patricia Carrell's " cohesion is not coherence". The author responds. TESOL Quarterly, 18(1), 161-168.

Cepni, S. (2016). A replication study: Oral corrrective feedback in L2 writing; two approaches compared. Procedia- Social Behavioral Sciences, 232, 520-528.

Crompton, P. (2011). Article errors in the English writing of advanced L1 Arabic learners: The role of transfer. Asian EFL Journal, 50, 4-34.

Darweesh, A., \& Khadhim, S. (2016). Iraqi EFL learners' problems in using conjunctions as cohesive devices. Journal of Education and Practice, 7(11), 169-180.

Edwards, L. (2008). Common European framework assessment tests. London: Mary Glasgow Magazines (Scholastic).

Ellis, R. (2008). The study of second language acquisition. Oxford: Oxford University Press.

Ellis, R., \& Barkhuizen, G. (2005). Analysing learner language. Oxford: Oxford University Press.

Erlam, R., Ellis, R., \& Batstone, R. (2013). Oral corrective feedback on L2 writing: Two approached compared. System, 41, 257268. https://doi.org/10.1016/j.system.2013.03.004. 
Ferris, D., \& Hedgcock, J. (2005). Teaching ESL composition: Purpose, process and practice. New Jersey: Lawrence Erlbaum Associates.

Goldstein, L. (2006). Feedback and revision in second language writing: Contextual, teacher, and student variables. In K. Hyland, \& F. Hyland (Eds.), Feedback in second language writing: Contexts and issues, (pp. 185-205). Cambridge: Cambridge University Press.

Goldstein, L., \& Conrad, S. (1990). Student input and negotiation of meaning in ESL writing conferences. TESOL Quarterly, 24(3), 443-460.

Gonzalez, E., Da Vinci, U., Victoria, C., \& Tamaulipas (2010). Impact of teacher/student conferencing and teacher written feedback on EFL revision. MEXTESOL Journal, 34(1), 59-71.

Halliday, M. A., \& Hasan, R. (1976). Cohesion in English. Hong Kong: Longman Group.

Hinkel, E. (2001). Matters of cohesion in L2 academic texts. Applied Language Learning, 12(2), 111-132.

Hinkel, E. (2002). Second language writer' text: Linguistic and rhetorical features. New Jersey: Lawrence Erlbaum.

Hinkel, E. (2004). Teaching academic ESL writing: Practical techniques in vocabulary and grammar. New Jersey: Lawrence Erlbaum.

Hobson, E. (2001). Writing center pedagogy. In G. Tate, A. Rupiper, \& K. Schick (Eds.), A guide to composition pedagogy, (pp. 165-182). New York: Oxford University Press.

Hyland, K. (2003). Second lanquage writing. New York: Cambridge University Press.

Hyland, K., \& Hyland, F. (2006). Feedback on second language students' writing. Language Teaching, 39(2), 83-101. https://doi. org/10.1017/S0261444806003399.

Johansson, S. (1973). The identification and evaluation of errors in foreign languages: A functional approach. In J. Svartvik (Ed. ), Papers in error analysis, (pp. 102-114). Stockholm: ERRATA.

Kwan, L., \& Yunus, M. (2014). Cohesive erorrs in writing among ESL pre-service teachers. English Language Teaching, 7(11), 130-150. https://doi.org/10.5539/elt.v7n11p130.

Lee, I. (2014). Revisiting teacher feedback in EFL writing from sociocultural perspectives. TESOL Quarterly, 48(1), 201-213. https://doi.org/10.1002/tesq.153.

Leung, A. (2008). Teacher-student conferencing: Implications for teaching L2 writing. Doctoral dissertation, University of Leicester.

Liu, M., \& Braine, G. (2005). Cohesive features in argumentative writing produced by Chinese undergraduates. System, 33, 623-636. https://doi.org/10.1016/j.system.2005.02.002.

McNamara, D., Crossley, S., \& McCarthy, P. (2010). Linguistic features of writing quality. Written Communication, 27(1), 57-86. https://doi.org/10.1177/0741088309351547.

Mohamed-Sayidina, A. (2010). Transfer of L1 cohesive devices and transition words into L2 academic texts: The case study of Arab students. RELC Journal, 41(3), 253-266. https://doi.org/10.1177/0033688210380569.

Muthanna, A. (2016). Teaching and learning EFL writing at Yemeni universities: A review of current practices. In A. Ahmed, \& H. Abouabdelkader (Eds.), Teaching EFL writing in the 12st century Arab world: Realities and challenges, (pp. 221-243). London: Palgrave Macmillan.

Nassaji, H., \& Swain, M. (2000). A Vygotskian perspective on corrective feedback in L2: The effect of random versus negotiated help on the learning of English articles. Language Awareness, 9(1), 34-51. https://doi.org/10.1080/09658410008667135.

Ong (2011). Investigating the use of cohesive devices by Chinese EFL learners. The Asian EFL Journal Quarterly, 3, 42-65.

Reid, J. (1992). A computer text analysis of four cohesion devices in English discourse by native and nonnative writers. Journal of Second Language Writing, 1(2), 79-107.

Shaw, P., \& Liu, E. (1998). What develops in the development of second-language writing? Applied Linguistics, 19(2), 225-254.

Sheen, Y., \& Ellis, R. (2011). Corrective feedback in language teaching. In E. Hinkel (Ed.), Handbook of research in second language teaching and learning volume II, (pp. 593-610). New York: Routledge.

Solloway, A. (2016). Do two wrongs make a write(r)? Some effects and non-effects of WCF on Arabic L1 students English academic writing. In A. Ahmed, \& H. Abouabdelkader (Eds.), Teaching EFL writing in the 21st century Arab world: Realities and challenges, (pp. 189-219). London: Palgrave Macmillan.

Vygotsky, L. (1978). Mind in society: The development of higher psychological processes. Cambridge: Harvard University Press.

Weigle, S. (2002). Assessing writing. Cambridge: Cambridge University Press.

Yang, W., \& Sun, Y. (2012). The use of cohesive devices in argumentative writing by Chinese EFL learners at different proficiency levels. Linguistics and Education, 23, 31-48. https://doi.org/10.1016/j.linged.2011.09.004.

\section{Publisher's Note}

Springer Nature remains neutral with regard to jurisdictional claims in published maps and institutional affiliations. 